\title{
Chapter \#2
}

\section{BASIC PSYCHOLOGICAL NEED SATISFACTION IN ARABIC LEARNING \\ Development and validation of a new measure for Arabic learners in Japan}

Katsunori Sumi

Nagoya Institute of Technology, Japan

\begin{abstract}
The present study developed and validated a new 9-item measure called the Basic Psychological Need Satisfaction of Arabic Learners Scale (BPNSALS). This scale was designed to assess the satisfaction of three basic psychological needs (i.e., autonomy, competence, and relatedness), which is central to self-determination theory (SDT), of Arabic learners in Japan. A total of 314 students taking Arabic courses in Japanese universities participated in a study to examine the reliability and construct validity of the BPNSALS. Both exploratory and confirmatory factor analyses of the BPNSALS items confirmed the subscale structure corresponding to the three basic psychological needs. Each BPNSALS subscale displayed adequate internal consistency (Cronbach's alpha) and temporal stability over 4-week period. The construct validity of the BPNSALS was provided by support for the hypothesized relationships with the different forms of Arabic learning motivation as proposed by SDT. In addition, the self-determination of motivation and Arabic learning outcomes, namely, satisfaction, subjective comprehension, and subjective achievement were also considered. Based on the findings, the study concluded that the BPNSALS is a useful tool for assessing basic psychological need satisfaction of Arabic learners in Japan.
\end{abstract}

Keywords: basic psychological need, need satisfaction, self-determination theory, Arabic learning, Japanese measure.

\section{INTRODUCTION}

\subsection{Arabic learners in Japanese universities}

In Japan, Arabic is predominantly studied as a foreign language. Most Arabic learners in Japan are university students, although there also non-students learning Arabic for work purposes (Sumi \& Sumi, 2016a, 2018). It is estimated that presently, more than 3,000 university students per year pursue courses in Arabic. The courses are offered by approximately 50 Japanese universities (Sumi \& Sumi, 2016a, 2018). Although these universities accounted for less than 7\% of all Japanese universities in 2016 (Ministry of Education, Culture, Sports, Science, and Technology of Japan, 2019), Arabic language instruction in higher education institutions in Japan has a history of over 90 years. However, scant attention has been paid to the psychological and behavioral characteristics of Arabic learners in Japanese universities. Some exceptions do exist, for instance, interest in Arabic culture (Sumi \& Sumi, 2016b; Sumi \& Sumi, 2015), orientation (Sumi \& Sumi, 2016), and some learning outcomes including learning satisfaction, learning anxiety, and subjective achievement (Sumi \& Sumi, 2015; Sumi \& Sumi, 2016b). To improve Arabic teaching and learning methods, it is necessary to acquire knowledge of the characteristics of Arabic learners themselves. 


\subsection{Satisfaction of basic psychological needs within self-determination theory}

One of the benefits of understanding Arabic learners in Japanese universities relates to basic psychological needs (BPN: Ryan \& Deci, 2017; Vansteenkiste, Ryan, \& Soenens, 2020) as a central construct in self-determination theory (SDT: Deci \& Ryan, 1985; Ryan \& Deci, 2000a, 2017). SDT is a leading theory of motivation, personality development, and well-being. SDT proposes five forms of motivation dependent on the degree of self-determination in a learner. These are, in increasing order of self-determination, as follows: amotivation, external regulation, introjected regulation, identified regulation, and intrinsic motivation. Amotivation and intrinsic motivation display the lowest and the highest degree of self-determination of motivation, respectively. SDT has also been widely applied to help understand motivations for foreign language learning (Busse \& Walter, 2013; Davis, 2020; Jones, Llacer-Arrastia, \& Newbill, 2009).

Within SDT, BPN is defined by three innate needs, specifically: autonomy, competence, and relatedness. There are indispensable nutrients required for psychological growth and well-being (Deci \& Ryan, 1985; Ryan \& Deci, 2000a, 2017). Autonomy refers to the need for feeling volitional and self-endorsed control of one's actions. Competence involves the need to feel mastery and effectance. Relatedness concerns the need to feel socially connected and being significant to others. In the SDT framework, although autonomy is presumed to be an essential psychological component of human nature (Reeve, Ryan, \& Deci, 2018; Ryan \& Deci, 2017), all three BPNs need to be satisfied to an approximately equal level to facilitate and maintain positive outcomes (Ryan \& Deci, 2000a, 2017; Vansteenkiste et al., 2020). The satisfaction of BPN (i.e., need satisfaction) provides a broad range of benefits to individuals' lives. These include intrinsic motivation, internalization, engagement, personal growth, health, and well-being (Reeve, 2018; Ryan \& Deci, 2017; Vansteenkiste et al., 2020). By contrast, poor satisfaction or frustration of BPSN leads to various negative outcomes, such as passivity, psychopathology, and ill-being (Ryan \& Deci, 2017; Vansteenkiste \& Ryan, 2013).

Numerous theoretical and empirical studies have supported the positive effects of satisfaction with autonomy, competence, and relatedness (i.e., autonomy satisfaction, competence satisfaction, and relatedness, respectively) on various learning and academic outcomes, including academic motivation (Niemiec \& Ryan, 2009; Opdenakker \& Minnaert, 2014; Raižienè, Gabrialavičiūtè, \& Garckija, 2017; Ryan \& Deci, 2000b; Tian, Han, \& Huebner, 2014). Greater need satisfaction has been found to be associated with more self-determined forms of academic motivation (e.g., Carreira, 2012; Gnambs \& Hanfstingl, 2016; Liu, Wang, Tan, Koh, \& Ee, 2009; Wang, Liu, Kee, \& Chian, 2019) and better learning outcomes, including academic satisfaction, achievement, and comprehension (e.g., Cerasoli, Nicklin, \& Nassrelgrgawi, 2016; Leach \& Patall, 2013; Yu \& Levesque-Bristol, 2020).

Therefore, measuring and understanding the need satisfaction of Arabic learners would be beneficial for both Arabic teachers and learners. Many different measures have been used to assess need satisfaction (e.g., Chen et al., 2015, Deci et al., 2001; Sheldon \& Hilpert, 2012). There are a few Japanese measures of need satisfaction (e.g., Nishimura \& Suzuki, 2016; Hiromori, 2005); however, there is no appropriate nor convenient measure of need satisfaction for Arabic learners.

\subsection{Purpose of the study}

The purpose of this study was to develop a reliable and valid measure to assess the need satisfaction of Arabic learners in Japan. Data from university students learning Arabic were used to develop the measure. The temporal stability of the measure was examined over a 4 -week period. The construct validity of the measure was examined by correlating scores for 
Basic Psychological Need Satisfaction in Arabic Learning Development and validation of a new measure for Arabic learners in Japan

Arabic learning motivation based on SDT, self-determination of motivation, and learning outcomes. These included satisfaction with Arabic learning, subjective comprehension of Arabic learning content, and subjective achievement in Arabic learning.

To construct validity for the new measure, it was expected that scores on the measure would be negatively related to scores for less self-determined forms, and be weakly or not related to moderate self-determined forms. It was also expected that scores would be positively related to more self-determined forms of motivation. Furthermore, in light of SDT, scores for need satisfaction were expected to be positively correlated with the degree of self-determination of motivation. Moreover, construct validity of the measure could be also supported by positive correlations with scores on the measures of the Arabic learning outcomes.

\section{METHOD}

\subsection{Participants}

The participants were 314 students recruited from students taking an Arabic course that were taught by an instructor who agreed to administer the questionnaire. The participants consisted of 196 women and 118 men with a mean age of 20.18 years $(\mathrm{SD}=2.23$, range $=19$ to 39 ). They came from various majors, including 131 with Arabic majors, which were in each of the seven Japanese universities.

\subsection{Measures}

\subsubsection{Basic psychological need satisfaction in Arabic learning}

The first step in the procedure to develop a measure to assess the need satisfaction of Arabic learners in Japan was to generate an item pool to tap the construct. The item pool was primarily derived from the following measures: the Japanese version of the 24-item Basic Psychological Need Satisfaction and Frustration Scale (Chen et al., 2015, Nishimura \& Suzuki, 2016), the 24-item Basic Psychological Need Satisfaction and Frustration Scale in training (Aelterman, Vansteenkiste, Van Keer, \& Haerens, 2016), the 12-item Need Satisfaction and Frustration scale (Mabbe, Soenens, Vansteenkiste, Van der Kaap-Deeder, \& Mouratidis, 2018), the 18-item Balanced Measure of Psychological Needs (Sheldon \& Hilpert, 2012), the 9-item subscales of the need satisfaction scale (Sheldon, Elliot, Kim, \& Kasser, 2001), the 9-item Need Satisfaction Scale (La Guardia, Ryan, Couchman, \& Deci, 2000), the 21-item Intrinsic Need Satisfaction scale (Deci et al., 2001), the 9-item Autonomy, Competence \& Relatedness scale (Kobau, Sniezek, Zack, Lucas, \& Burns, 2010), the 18-item Work-related Basic Need Satisfaction scale (Van den Broeck, Vansteenkiste, De Witte, Soenens, \& Lens, 2010), the 18-item Psychological Need Satisfaction in Exercise scale (Wilson, Rogers, Rodgers, \& Wild, 2006), the 15-item Adolescent Students' Basic Psychological Needs at School Scale (Tian et al., 2014), and the 12-item scale of psychological needs of English students (Hiromori, 2005).

Two researchers who were familiar with SDT and bilingual in English and Japanese carefully selected items appropriate for the three types of need satisfaction in the item pool. If the selected items were in English, they were translated into Japanese. Next, all the selected items were modified to refer to the Arabic learners in Japan and were then inspected by the researchers. Each of the 18 resulting items was a short sentence that clearly and concisely expressed the need satisfaction of the Arabic learners using plain Japanese. Following this, four Arabic students in Japanese universities checked and commented on the items. Based on their comments, the items were revised and further examined by the researchers. Finally, 
several students learning Arabic checked the items and found no problem in the expression of the items. A total of nine items, which consisted of three items each for the types of need satisfaction, were identified. These were autonomy satisfaction (e.g., "I am satisfied with deciding the content and ways of learning Arabic language by myself" in Japanese), competence satisfaction (e.g., "I am satisfied with demonstrating my ability in learning Arabic language" in Japanese), and relatedness satisfaction (e.g., "I am satisfied with exchanges with the people involved in Arabic language learning" in Japanese). The nine items were rated on a 7-point Likert scale, ranging from 1 (strongly disagree) to 7 (strongly agree). There were no reverse worded items. This measure was subsequently named the Basic Psychological Need Satisfaction of Arabic Learners Scale (BPNSALS).

\subsubsection{Arabic learning motivation}

To assess Arabic learning motivation, the Arabic Learning Motivation Questionnaire (ALMQ: Sumi \& Sumi, 2019) was used. This is a 15 -item measure consisting of five subscales that was designed to assess the five forms of motivation based on SDT. The items were rated on a 7-point scale ranging from 1 (strongly disagree) to 7 (strongly agree). Each subscale has a single factor structure as expected, good internal consistency reliability (Cronbach's alphas $=.86$ to .90$)$, and test-retest reliability over four weeks ( $r$ s $=.69$ to .79 ). As evidence of construct validity, the results confirmed the expected correlations between scores on learning outcome measures as well as the simplex structure between the ALMQ subscales which is a theoretically hypothesized correlational pattern between them (Gagné, et al., 2010; Noels, Pelletier, Clément, \& Vallerand, 2000; Ryan \& Connell, 1989).

Furthermore, composite scores for controlled and autonomous motivation were calculated by averaging across external and introjected regulation items and averaging across identified regulation and intrinsic motivation items, respectively. This followed the procedure of the previous studies (e.g., Bidee et al., , 2013; Pelletier, Fortier, Vallerand, \& Briere, 2001; Vansteenkiste, Sierens, Soenens, Luyckx, \& Lens, 2009). Additionally, researchers assessed individuals' overall self-determination of motivation using a single score that was calculated using scores for the motivation forms. This score was called the Relative Autonomy Index (RAI) score (Grolnick \& Ryan, 1987; Howard, Gagné, \& Bureau, 2017), and was calculated using the following equation: RAI = (intrinsic motivation scale scores $\times 2)+($ identified regulation scale scores $\times 1)+($ introjected regulation scale scores $\times$ $1)+($ external regulation scale scores $\times 2)$.

\subsubsection{Arabic learning outcomes}

The Japanese measures that were used to assess three Arabic learning-related outcomes were learning satisfaction, subjective comprehension, and subjective achievement. Each of the measures consisted of three items with a 7-point scale ranging from 1 (strongly disagree) to 7 (strongly agree). Good internal consistency reliability (Cronbach's alpha $=.88$ to .96 ) and single factor structure were found for the measures (Sumi \& Sumi, 2016b; Sumi \& Sumi, 2015 , 2016). Each of these measures scores showed the expected correlations with the ALMQ subscales scores (Sumi \& Sumi, 2019). The measures are more fully described below. (1) Learning satisfaction

The Arabic Learning Satisfaction Scale (Sumi \& Sumi, 2015) was used to assess overall satisfaction while learning Arabic (e.g., "I am satisfied with my Arabic lessons" in Japanese). Higher scores indicate greater satisfaction with Arabic learning. 
Basic Psychological Need Satisfaction in Arabic Learning Development and validation of a new measure for Arabic learners in Japan

\section{(2) Subjective comprehension}

The Arabic Learning Comprehension Scale (Sumi \& Sumi, 2016b) was used to assess general understanding of the content of Arabic learning, which was evaluated by the students themselves (e.g., "I understand the content of Arabic well" in Japanese). Higher scores indicate greater subjective comprehension of Arabic learning content.

(3) Subjective achievement

The Arabic Learning Achievement Scale (Sumi \& Sumi, 2015) was used to measure general achievements or grades on tasks and tests in the Arabic class, which were evaluated by the students themselves (e.g., "I think my grade in Arabic is good" in Japanese). Higher scores indicate greater subjective achievement in Arabic learning.

\subsection{Procedure of the questionnaire administration}

After obtaining informed consent from the participants, they were asked to participate in two questionnaire sessions, four weeks apart (i.e., Time 1 and Time 2). The participants completed the BPNSALS and other measures at Time 1, but only BPNSALS at Time 2 . The questionnaires were administered anonymously to participants when they were outside the class. Ethical clearance for the study was obtained from the ethical committee of the institutions involved in the study.

\subsection{Data analysis}

First, the factor analyses were performed to examine the hypothesized factor structure of the BPNSALS. After the exploratory factor analysis was conducted on the data of half of the sample to identify the underlying factor structure of the BPNSALS, a confirmatory factor analysis was then conducted on the data of the other half to confirm the factor structure. Second, to assess the reliability of the BPNSALS, Cronbach's alphas and test-retest correlations over a 4-week period were calculated. Finally, correlations between scores on the BPNSALS subscales and Arabic learning-related scales were examined to evaluate the construct validity of the BPNSALS.

\section{RESULTS}

\subsection{Factor structure}

For factor analysis, the sample was randomly divided into two sub-samples of equal size: Sample $1(n=157)$ and Sample $2(n=157)$. There were no significant differences between the groups with regards to sex, $\chi^{2}(1, N=314)=.49$, and age, $t(312)=.43$. For Samples 1 and 2, the results of the Kaiser-Meyer-Olkin test of sampling adequacy was good ( .87 for both samples), and the Bartlett's test of sphericity was significant $\left(\chi^{2} \mathrm{~s}=1306.24\right.$ and $1422.84, d f \mathrm{~s}=36$ and $36, p s<.01$, respectively). These results suggested that both datasets from the two samples were suitable for factor analysis of the BPNSAL scale.

Exploratory factor analysis using principal component analysis was performed on the data from Sample 1. The eigenvalues for the first five factors were 5.74, 1.17, 1.05, 0.30, and 0.21 . Based on eigenvalues greater than 1.0, the scree test, and factor interpretability, three factors were retained, accounting for $88.92 \%$ of the total variance. The promax rotation method was applied to these extracted factors, which were expected to be interrelated. As shown in Table 1, all items had factor loadings of .87 or higher on a single factor and .13 or lower for all other factors. The items that loaded highly on each factor were the same as those were previously hypothesized to constitute the corresponding subscales. The first, 
second, and third factors corresponded to subscales for the satisfaction of relatedness, autonomy, and competence, respectively.

To test the three-factor structure of the BPNSALS, confirmatory factor analysis was performed on Sample 2. The goodness of fit indices indicated a good fit for the three-factor model, $\chi^{2}(24, N=157)=34.35, p>.05$, GFI $=.96$, AGFI $=.92$, RMSEA $=.05$, SRMR $=.03$, NFI $=.97$, and CFI $=.99$. As shown in Table 2, all the standardized factor loadings were over .85 and significant at the .01 level. Correlations between factor scores ranged from .52 to .68 . Based on the results of the factor analyses, the items that loaded on each factor formed the three subscales of the BPNSALS corresponding to the three types of need satisfaction: autonomy satisfaction scale, the competence satisfaction scale, and the relatedness satisfaction scale. Each subscale score was calculated by summing the responses across the subscale items, with higher scores indicating greater levels of satisfaction.

Table 1.

Factor Loadings for Exploratory Factor Analysis for Sample 1.

\begin{tabular}{cccc}
\hline Item & Factor 1 & Factor 2 & Factor 3 \\
\hline 1 & .13 & $\mathbf{. 9 2}$ & -.08 \\
2 & -.01 & $\mathbf{9 5}$ & .03 \\
3 & -.08 & $\mathbf{. 9 3}$ & .08 \\
4 & .04 & .02 & $\mathbf{9 0}$ \\
5 & -.07 & .04 & $\mathbf{. 9 7}$ \\
6 & .10 & -.04 & $\mathbf{. 8 7}$ \\
7 & $\mathbf{9 1}$ & .08 & .02 \\
8 & $\mathbf{. 9 8}$ & .02 & -.04 \\
9 & $\mathbf{9 5}$ & -.06 & .06 \\
Eigenvalue & 5.78 & 1.17 & 1.05 \\
\% of variance & 64.26 & 12.97 & 11.69 \\
\hline
\end{tabular}

Note: $n=157$. Factor loadings in bold indicate the factor in which the item was judged to belong.

Table 2.

Standardized Factor Loadings for Confirmatory Factor Analysis for Sample 2.

\begin{tabular}{cccc}
\hline Item & $\begin{array}{c}\text { Autonomy } \\
\text { satisfaction }\end{array}$ & $\begin{array}{c}\text { Competence } \\
\text { satisfaction }\end{array}$ & $\begin{array}{c}\text { Relatedness } \\
\text { satisfaction }\end{array}$ \\
\hline 1 & .91 & & \\
2 & .94 & & \\
3 & .87 & & \\
4 & & .91 & \\
5 & & .88 & \\
6 & & .85 & \\
7 & & & .95 \\
8 & & & .91 \\
9 & & & .89 \\
\hline
\end{tabular}

Note. $n=157$. All factor loadings are significant, $p<.01$.

\subsection{Internal consistency and temporal stability}

Table 3 presents the means, standard deviations, range of corrected item-total correlations, and Cronbach's alphas for the BPNSALS subscales at Time 1. Corrected item-total correlations and Cronbach's alphas were sufficiently high. Test-retest correlations 
Basic Psychological Need Satisfaction in Arabic Learning Development and validation of a new measure for Arabic learners in Japan

between the BPNSALS subscale scores at Time 1 and Time 2 are also presented. These correlations were greater than .80. The intercorrelations contained in Table 3 indicate that the BPNSALS subscale scores were highly and positively correlated with one another.

Table 3.

Means, Standard Deviations, Range of Scores, Cronbach's as, Test-Retest Correlations and Intercorrelations for BPNSALS at Time 1.

\begin{tabular}{|c|c|c|c|c|c|c|c|}
\hline \multirow[t]{2}{*}{ BPNSALS subscale } & \multirow[t]{2}{*}{$M$} & \multirow[t]{2}{*}{$S D$} & \multirow[t]{2}{*}{ CITC } & \multirow[t]{2}{*}{$\alpha$} & \multirow{2}{*}{$\begin{array}{c}\text { Test-retest } \\
r\end{array}$} & \multicolumn{2}{|c|}{$r$} \\
\hline & & & & & & 1 & 2 \\
\hline 1. Autonomy satisfaction & 13.81 & 4.25 & $.83-.87$ & .88 & .90 & & \\
\hline 2. Competence satisfaction & 14.10 & 3.86 & $.80-.84$ & .90 & .82 & $.58^{* *}$ & \\
\hline 3. Relatedness satisfaction & 10.09 & 4.70 & $.88-.90$ & .85 & .90 & $.54^{* *}$ & $.61^{* *}$ \\
\hline
\end{tabular}

Note: Test-retest correlations are calculated using the BPNSALS subscale scores at Time 1 and Time 2. CITC $=$ Corrected item-total correlation. $\alpha=$ Cronbach's alpha.

$* * p<.01$.

\subsection{Correlations with scores on other measures}

Correlations between scores on the BPNSALS subscales and other learning-related scales are presented in Table 4. Scores for the three subscales of the BPNSALS had similar correlations with scores on the Arabic learning motivation and outcomes scales. Scores on the amotivation and external regulation scales were moderately and negatively correlated with BPNSALS subscale scores. Although scores on the introjected regulation scale were not significantly correlated with BPNSALS subscale scores, they were significantly and positively correlated with scores on the identified regulation and intrinsic motivation scales. BPNSALS subscales scores were weakly and negatively correlated with controlling motivation scores and, in contrast, highly and positively correlated with autonomous motivation scores. The RAI scores were highly and positively correlated with the BPNSALS subscale scores. Furthermore, there were positive correlations between scores on the BPNSALS subscale and learning outcome scales.

\section{DISCUSSION}

The purpose of the present study was to develop and validate a new measure (the BPNSALS) for assessing need satisfaction in Arabic learners in Japan based on the SDT framework. The results of this study provide preliminary support for the BPNSALS, which consists of three subscales: autonomy, competence, and relatedness satisfaction scales. The subscale structure of the BPNSALS which was derived from the exploratory and confirmatory factor analyses revealed a strong correspondence with the theoretical subscale structure.

The present findings suggest that BPNSALS is a highly reliable measure. All the subscales indicated good internal consistency reliability with suitable Cronbach's alphas, which were high, but not too high, for a three-item short scale (Cohen, 2018; Nunnally \& Bernstein, 1994; Streiner, 2003). The test-retest correlations over a 4-week interval were very high. These correlations are higher than test-retest correlations (.66 to .76) over a 3-week interval for the Japanese version of the Basic Psychological Need Satisfaction and Frustration Scale (Nishimura \& Suzuki, 2016), which assesses need satisfaction in life in general. That said, for Japanese university students, Arabic learning settings are more likely to be stable than for general life settings. 
K. Sumi

Table 4.

Correlations between Scores on BPNSALS Subscales and Arabic Learning Motivation and Outcome Scales.

\begin{tabular}{lccccc}
\hline \multicolumn{1}{c}{ Measure } & $M$ & $S D$ & & $r$ & \\
\cline { 4 - 6 } & & & $\begin{array}{c}\text { Autonomy } \\
\text { satisfaction }\end{array}$ & $\begin{array}{c}\text { Competence } \\
\text { satisfaction }\end{array}$ & $\begin{array}{c}\text { Relatedness } \\
\text { satisfaction }\end{array}$ \\
\hline Amotivation & & & $-.50^{* *}$ & $-.49^{* *}$ & $-.42^{* *}$ \\
External regulation & 5.14 & 2.67 & $-.44^{* *}$ & $-.39^{* *}$ & $-.31^{* *}$ \\
Introjected regulation & 6.03 & 3.37 & -.04 & .02 & .03 \\
Identified regulation & 8.59 & 3.88 & $.52^{* *}$ & $.38^{* *}$ \\
Intrinsic motivation & 15.03 & 3.87 & $.46^{* *}$ & $.57^{* *}$ & $.50^{* *}$ \\
Controlling motivation & 2.53 & 18.65 & $.67^{* *}$ & $.51^{* *}$ & $-.16^{* *}$ \\
Autonomous motivation & 7.31 & 2.93 & $-.28^{* *}$ & $-.51^{* *}$ & $.50^{* *}$ \\
RAI & 17.78 & 4.10 & $.64^{* *}$ & $.67^{* *}$ \\
Satisfaction with Arabic learning & 35.44 & 5.23 & $.64^{* *}$ & $.56^{* *}$ & $.25^{* *}$ \\
Subjective comprehension & 13.99 & 4.05 & $.40^{* *}$ & $.41^{* *}$ & $.21^{* *}$ \\
Subjective achievement & 13.09 & 3.84 & $.45^{* *}$ & $.29^{* *}$ & $.43^{* *}$ \\
\hline ** $p<.01$ & 13.18 & 3.65 & $.58^{* *}$ & $.45^{* *}$ & \\
\hline
\end{tabular}

** $p<.01$.

The results preliminarily support the construct validity of BPNSALS. The hypothesized correlations between scores on the BPNSALS subscales and ALMQ subscales were supported. All the BPNSALS subscale scores were negatively correlated with the scores for less self-determined forms of motivation (i.e., amotivation and external regulation). they were not significantly correlated with the scores for a moderate self-determined form of motivation (i.e., introjected regulation). They were positively correlated with scores for more self-determined forms of motivation (i.e., identified regulation and intrinsic motivation). The difference in the correlations due to the level of self-determination in the form of motivation clearly appeared in the correlations with composite scores for controlled and autonomous motivation. As expected, the scores on the BPNSALS subscales were negatively and positively correlated with the scores for controlled and autonomous motivation, respectively. Furthermore, this tendency is also supported by positive correlations with the RAI scores measuring learners' overall self-determination. Each of these are the relationships that have been theoretically (Deci \& Ryan, 1985; Ryan \& Deci, 2000a, 2017) and empirically (e.g., Carreira, 2012; Gnambs \& Hanfstingl, 2016; Liu et al., 2009; Wang et al., 2019) supported. Thus, the correlations with forms of Arabic learning motivation and self-determination indicate the construct validity of the BPNSALS.

The BPNSALS also showed adequate construct validity through significant correlations with scores for subjective learning outcomes. The results showed that the BPNSALS subscale scores were positively correlated with scores for satisfaction, comprehension, and achievement in relation to Arabic learning as predicted by SDT (Deci \& Ryan, 1985; Ryan \& Deci, 2000a, 2017) and as have been supported by previous empirical studies (e.g., Cerasoli et al., 2016; Leach \& Patall, 2013; Yu \& Levesque-Bristol, 2020). Additionally, these correlations were lower than .70, which is considered the upper bound of the correlation between scores on measures assessing different constructs (Van den Broeck et al, 2010). Hence, the discriminant validity of the BPNSALS was supported by their correlations with the scores for the Arabic learning outcomes.

Before concluding this article, it is necessary to note the limitations of this study. First, as the sample was limited to university students, further research is required to assess the generalizability of the BPNSALS with other groups, such as workers learning Arabic for 
Basic Psychological Need Satisfaction in Arabic Learning Development and validation of a new measure for Arabic learners in Japan

work purposes. Second, it is necessary to examine test-retest correlations over a longer interval to further clarify the temporal stability of the BPNSALS. Third, to assess construct validity of the BPNSALS more widely, the relationships to learning-related attitudes and well-being other than the learning outcomes that were addressed in this study should also be examined. Fourth, future research to examine the other psychometric properties of the BPNSALS, such as predictive validity, is warranted. Finally, the BPNSALS have no reverse items which could bring some bias in participants' answers. In future studies, it might be better to improve the BPNSALS in this regard.

In conclusion, despite the limitations mentioned above, this study provides preliminary evidence for the good psychometric properties of the BPNSALS, which was designed to measure the need satisfaction of Arabic learners in Japan from the perspective of SDT. The BPNSALS is a useful need satisfaction measure, like the existing measures (e.g., Chen et al., 2015, Deci et al., 2001; Nishimura \& Suzuki, 2016; Sheldon \& Hilpert, 2012), and a convenient measure that could became readily available in various research settings to Arabic learners. It can be expected that through the practical use of the BPNSALS, an understanding of the Arabic learners in Japan will be advanced: in turn, their learning environments and well-being will be enhanced.

\section{REFERENCES}

Aelterman, N., Vansteenkiste, M., Van Keer, H., \& Haerens, L. (2016). Changing teachers' beliefs regarding teacher autonomy support and structure: The role of experienced psychological need satisfaction in teacher training. Psychology of Sport and Exercise, 23, 64-72. doi: 1.1016/j.psychsport.2015.1.007

Busse, V., \& Walter, C. (2013). Foreign language learning motivation in higher education: A longitudinal study of motivational changes and their causes. Modern Language Journal, 97(2), 435-456. doi: 10.1111/j.1540-4781.2013.12004.x

Bidee, J., Vantilborgh, T., Pepermans, R., Huybrechts, G., Willems, J., Jegers, M., \& Hofmans, J. (2013). Autonomous motivation stimulates volunteers' work effort: A self-determination theory approach to volunteerism. Voluntas: International Journal of Voluntary and Non-profit Organizations, 24(1), 32-47. doi: 1.1007/s11266-012-9269-х

Carreira, J. M. (2012). Motivational orientations and psychological needs in EFL learning among elementary school students in Japan. System, 40(2), 191-202. doi: 10.1016/j.system.2012.02.001

Cerasoli, C., P., Nicklin, J., M. \& Nassrelgrgawi, A., S. (2016). Performance, incentives, and needs for autonomy, competence, and relatedness: A meta-analysis. Motivation and Emotion, 40(6), 781-813. doi: 10.1007/s11031-016-9578-2

Chen, B., Vansteenkiste, M., Beyers, W., Boone, L., Deci, E. L., Van der Kaap-Deeder, J., Duriez, B., Lens, W., Matos, L., Mouratidis, A., Ryan, R. M., Sheldon, K. M., Soenens, B., Van Petegem, S., \& Verstuyf, J. (2015). Basic psychological need satisfaction, need frustration, and need strength across four cultures. Motivation and Emotion, 39(2), 216-236. doi: 1.1007/s11031-014-9450-1

Cohen, R. J. (2018). Psychological testing and assessment: An introduction to tests and measurement (9th ed.). New York: McGraw-Hill.

Davis, W. S. (2020). Encouraging continued university foreign language study: A self-determination theory perspective on programme growth. Language Learning Journal. Advance online publication. doi: 10.1080/09571736.2020.1740768

Deci, E. L., \& Ryan, R. M. (1985). Intrinsic motivation and self-determination in human behavior. New York: Plenum Press. 
Deci, E. L., Ryan, R. M., Gagné, M., Leone, D. R., Usunov, J., \& Kornazheva, B. P. (2001). Need satisfaction, motivation, and well-being in the work organizations of a former eastern bloc country: A cross-cultural study of self-determination. Personality and Social Psychology Bulletin, 27(8), 930-942. doi: 1.1177/0146167201278002

Gagné, M., Forest, J., Gilbert, M. H., Aubé, C., Morin, E., \& Malorni, A. (2010). The Motivation at Work Scale: Validation evidence in two languages. Educational and Psychological Measurement 70(4), 628-646. doi: 1.1177/0013164409355698

Gnambs, T., \& Hanfstingl, B. (2016). The decline of academic motivation during adolescence: An accelerated longitudinal cohort analysis on the effect of psychological need satisfaction. Educational Psychology, 36(9), 1691-1705. doi: 10.1080/01443410.2015.1113236

Grolnick, W. S., \& Ryan, R. M. (1987). Autonomy in children's learning: An experimental and individual difference investigation. Journal of Personality and Social Psychology, 52(5), 890-898. doi: 1.1037/0022-3514.52.5.890

Hiromori, T. (2005). Gaikokugo-gakushusha no doukiduke wo takameru 3-tsu no youin: Zentai-keikou to kojin-sa no kanten kara [Three factors that motivate L2 learners: From the perspectives of general tendency and individual differences]. JACET Bulletin, 41, 37-50. Retrieved from https://dl.ndl.go.jp/view/prepareDownload?itemId=info\%3Andljp\%2Fpid\%2F10501477\&conte $\mathrm{ntNo}=1$

Howard, J. L., Gagné, M., \& Bureau, J. S. (2017). Testing a continuum structure of self-determined motivation: A meta-analysis. Psychological Bulletin, 143(12), 1346-1377. doi: $10.1037 /$ bul0000125

Jones, B. D., Llacer-Arrastia, S., \& Newbill, P. B. (2009). Motivating foreign language students using self-determination theory. International Journal of Innovation in Language Learning and Teaching, 3(2), 171-189. doi: 10.1080/17501220802358210

Kobau, R., Sniezek, J., Zack, M. M., Lucas, R. E., \& Burns, A. (2010). Well-being assessment: An evaluation of well-being scales for public health and population estimates of well-being among US adults. Applied Psychology: Health and Well-Being, 2(3), 272-297. doi: $1.1111 / \mathrm{j} .1758-0854.201 .01035 . x$

La Guardia, J., Ryan, R. M., Couchman, C. E., \& Deci, E. L. (2000). Within-person variation in security of attachment: A self-determination theory perspective on attachment, need fulfillment, and well-being. Journal of Personality and Social Psychology, 79(3), 367-384. doi: $1.1037 / 0022-3514.79 .3 .367$

Leach, J. K., \& Patall, E. A. (2013). Maximizing and counterfactual thinking in academic major decision making. Journal of Career Assessment, 21(3), 414-429. doi: $10.1177 / 1069072712475178$

Liu, W. C., Wang, C. K. J., Tan, O. S., Koh, C., \& Ee, J. (2009). A self-determination approach to understanding students' motivation in project work. Learning and Individual Differences, 19(1), 139-145. doi: 10.1016/j.lindif.2008.07.002

Mabbe, E. Soenens, B., Vansteenkiste, M., Van der Kaap-Deeder, J., \& Mouratidis, A. (2018). Day-today variation in autonomy-supportive and psychologically controlling parenting: The role of parents' daily experiences of need satisfaction and need frustration. Parenting: Science and Practice; 18(2), 86-109. doi: 1.1080/15295192.2018.1444131

Ministry of Education, Culture, Sports, Science, and Technology of Japan (2019). Daigaku ni okeru kyouiku-naiyō-tō no kaikaku-jōkyō ni tsuite (Heisei 28 nendo) [On the state of the reformation of educational contents in universities in 2016]. Tokyo: Author. Retrieved from https://www.mext.go.jp/a_menu/koutou/daigaku/04052801/1417336.htm

Niemiec, C. P., \& Ryan, R. M. (2009). Autonomy, competence, and relatedness in the classroom: Applying self-determination theory to educational practice. Theory and research in Education, 7(2), 133-144. doi: 10.1177/1477878509104318

Nishimura, T., \& Suzuki, T. (2016). Basic psychological need satisfaction and frustration in Japan: Controlling for big five personality traits. Japanese Psychological Research, 58(4), 320-331. doi: 1.1111/jpr.12131 
Basic Psychological Need Satisfaction in Arabic Learning Development and validation of a new measure for Arabic learners in Japan

Noels, K. A., Pelletier, L. G., Clément, R., \& Vallerand, R. J. (2000). Why are you learning a second language? Motivational orientations and self-determination theory. Language Learning, 50(1), 57-85. doi: 1.1111/0023-8333.00111

Nunnally, J. C. \& Bernstein, I. H. (1994). Psychometric theory (3rd ed). New York: McGraw-Hill.

Opdenakker, M. C., \& Minnaert, A. (2014). Learning environment experiences in primary education: Their importance to academic engagement. In D. Zandvliet, P. den Brok, T. Mainhard, \& J. van Tartwijk (Eds.), Interpersonal relationships in education: From theory to practice (pp. 183-194). Rotterdam, The Netherlands: Sense.

Pelletier, L. G., Fortier, M. S., Vallerand, R. J., \& Briere, N. M. (2001). Associations among perceived autonomy support, forms of self-regulation, and persistence: A prospective study. Motivation and Emotion, 25, 279-306. doi: 1.1023/A:1014805132406

Raižienè, S., Gabrialavičiūtè, I., \& Garckija, R. (2017). Links between basic psychological need satisfaction and school adjustment: A person-oriented approach. Journal of Psychological and Educational Research, 25, 82-92. Retrieved from https://pdfs.semanticscholar.org/7da0/42a04d24f67bce4dff568ce1cf07e0cee5ed.pdf

Reeve, J. (2018). Understanding motivation and emotion (7th ed.). Hoboken, NJ: John Wiley \& Sons.

Reeve, J., Ryan, R. M., \& Deci, E. L. (2018). Sociocultural influences on student motivation as viewed through the lens of self-determination theory. In G. A. D. Lim \& D. M. McInerney (Eds.), Big theories revisited 2 (pp. 15-40). Charlotte, NC: Information Age.

Ryan, R. M., \& Connell, J. P. (1989). Perceived locus of causality and internalization: Examining reasons for acting in two domains. Journal of Personality and Social Psychology, 57(5), 749-761. doi: 1.1037/0022-3514.57.5.749

Ryan, R. M., \& Deci, E. L. (2000a). Self-determination theory and the facilitation of intrinsic motivation, social development, and well-being. American Psychologist, 55(1), 68-78. doi: 1.1037/0003-066X.55.1.68

Ryan, R. M., \& Deci, E. L. (2000b). Intrinsic and extrinsic motivations: Classic definitions and new directions. Contemporary Educational Psychology, 25(1), 54-67. doi: 1.1006/ceps.1999.1020

Ryan, R. M., \& Deci, E. L. (2017). Self-determination theory: Basic psychological needs in motivation, development, and wellness. New York: Guilford Press.

Sheldon, K. M., Elliot, A. J., Kim, Y., \& Kasser, T. (2001). What is satisfying about satisfying events? Testing 10 candidate psychological needs. Journal of Personality and Social Psychology, 80(2), 325-339. doi: 1.1037/0022-3514.8.2.325

Sheldon, K. M., \& Hilpert, J. C. (2012). The balanced measure of psychological needs (BMPN) scale: An alternative domain general measure of need satisfaction. Motivation and Emotion, 36(4), 439-451. doi: 1.1007/s11031-012-9279-4

Streiner, D. L. (2003). Starting at the beginning: An introduction to coefficient alpha and internal

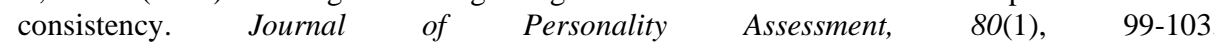
doi: $1.1207 /$ S15327752JPA8001_18

Sumi, A. M., \& Sumi, K. (2016a). Nihon no kōkō to daigaku ni okeru arabiago no kyōiku to gakushū-sha [Arabic language instruction and learners in Japanese high schools and universities]. Arabu Isuramu Kenkyū, (14), 103-121. Retrieved from https://ci.nii.ac.jp/naid/40020957188

Sumi, A. M., \& Sumi, K. (2016b). Interest in Arabic culture among Arabic language students in Japanese universities. Annuals of Japan Association for Middle East Studies, 31-2, 151-182. doi: 1.24498/ajames.31.2_151

Sumi, A. M., \& Sumi, K. (2018). Teaching and learning Arabic in Japan. In K. Wahba, L. England, \& Z. A. Taha (Eds.), Handbook for Arabic language teaching professionals in the 21st century, Volume II (pp. 20-37). New York: Routledge.

Sumi, K. \& Sumi, A. M. (2015). Development of the Interest in Arabic Culture Scale (IACS): A measure of interest in Arabic culture for students learning Arabic in Japanese universities. Journal of Psychology and Psychotherapy, 5(3), Article 5:18. doi: 1.4172/2161-0487.1000180

Sumi, K., \& Sumi, A. M. (2016). Orientations among Japanese university students learning Arabic. Annuals of Japan Association for Middle East Studies, 31-2, 115-150. doi: 1.24498/ajames.31.2_115 
Sumi, K., \& Sumi, A. M. (2019). The Arabic Learning Motivation Questionnaire: Development of a new Japanese measure based on self-determination theory. Psychology, 10(16), 2209-2223. doi: $1.4236 /$ psych.2019.1016140

Tian, L., Han, M., \& Huebner, E. S. (2014). Preliminary development of the Adolescent Students' Basic Psychological Needs at School Scale. Journal of Adolescence, 37(3), 257-267. doi:1.1016/j.adolescence.2014.01.005

Van den Broeck, A., Vansteenkiste, M., De Witte, H., Soenens, B., \& Lens, W. (2010). Capturing autonomy, competence, and relatedness at work: Construction and initial validation of the Work-related Basic Need Satisfaction scale. Journal of Occupational and Organizational Psychology, 83(4), 981-1002. doi: 1.1348/096317909X481382

Vansteenkiste, M., \& Ryan, R. M. (2013). On psychological growth and vulnerability: Basic psychological need satisfaction and need frustration as a unifying principle. Journal of Psychotherapy Integration, 23(3), 263-28. doi: 1.1037/a0032359

Vansteenkiste, M., Ryan, R. M., \& Soenens, B. (2020). Basic psychological need theory: Advancements, critical themes, and future directions. Motivation and Emotion, 44(1), 1-31. doi: 1.1007/s11031-019-09818-1

Vansteenkiste, M., Sierens, E., Soenens, B., Luyckx, K., \& Lens, W. (2009). Motivational profiles from a self-determination perspective: The quality of motivation matters. Journal of Educational Psychology, 101(3), 671-688. doi: 1.1037/a0015083

Wang, C. J., Liu, W. C., Kee, Y. H., \& Chian, L. K. (2019). Competence, autonomy, and relatedness in the classroom: Understanding students' motivational processes using the self-determination theory. Heliyon, 5(7), Article e01983. doi: 10.1016/j.heliyon.2019.e01983

Wilson, P. M., Rogers, W. T., Rodgers, W. M., \& Wild, T. C. (2006). The psychological need satisfaction in exercise scale. Journal of Sport and Exercise Psychology, 28, 231-251. Retrieved from https://pdfs.semanticscholar.org/7faa/a7c4ca529e4ab16d3c2664566a3b103bd32c.pdf

Yu, S., \& Levesque-Bristol, C. (2020). A cross-classified path analysis of the self-determination theory model on the situational, individual and classroom levels in college education. Contemporary Educational Psychology, 61, Article 101857. doi: 10.1016/j.cedpsych.2020.101857

\section{ACKNOWLEDGEMENTS}

The author wishes to thank Prof. Akiko M. Sumi, Kyoto Notre Dame University, for her cooperation in this study.

\section{AUTHOR INFORMATION}

Full name: Katsunori Sumi

Institutional affiliation: Nagoya Institute of Technology

Institutional address: Gokiso, Showa, Nagoya, Aichi, Japan

Biographical sketch: Katsunori Sumi is a Professor of the Graduate School of Engineering at Nagoya Institute of Technology (Japan) from 2007. He received his Ph.D. from Nagoya Institute of Technology. He teaches Behavioral Science, Organizational Behavior, and Applied Psychology. He is currently engaged in the research on well-being and academic motivation. His latest publication includes an article in Positive psychology and positive education in Asia: Understanding and fostering well-being in schools (Springer, 2020). 